\title{
Modern Approaches to the Integrated Assessment of Personnel Risks of an Industrial Enterprise
}

\author{
Alexey Tikhonov ${ }^{1}$ \\ ${ }^{1}$ Moscow Aviation Institute (National Research University), Moscow, Russian Federation \\ Correspondence: Alexey Tikhonov, Moscow Aviation Institute (National Research University), Moscow, 4, \\ Volokolamskoe Highway, 125993, Russian Federation. Tel: 7-967-186-7067. E-mail: danonik92@mail.ru, \\ mai512hr@mail.ru
}

Received: March 20, 2020

Accepted: April 17, 2020

Online Published: June 16, 2020

doi:10.5430/rwe.v11n3p99

URL: https://doi.org/10.5430/rwe.v11n3p99

\begin{abstract}
The aim of the work is the theoretical justification of the appropriateness of the integration assessment of personnel risks in order to ensure the personnel security of the organization and the development of methodological and practical recommendations for working with personnel. The current economic conditions of an industrial enterprise are inextricably connected with the impact of environmental threats on the work of personnel, which, on the one hand, is a source of risk generation and development, and on the other hand, is an object of risk exposure, which can affect the results of work. The definition of personnel risk and the types of its manifestations excite many scientists and practitioners, but now in Russia, scientific research in this area is still limited and requires further study. There is an objective need for systematic research and a comprehensive solution of theoretical, methodological, and applied problems of personnel risk management in working with personnel of industrial enterprises. The author conducted a study of the conceptual apparatus and approaches to classification, which allowed using his own approach to risk classification when assessing them based on well-known approaches of integration assessments of personnel work risk. The object of the study was the personnel of the Russian aviation industry enterprise, where, based on the scales and questionnaires developed by the author, experts from among employees were interviewed. The subjects of the study were the following: laws, principles, methods, processes, and organizational and managerial relations regarding personnel risk management in the personnel management system of the enterprise. The implementation of the goal identified the need to solve the following tasks:

- analysis of the opinions of Russian and foreign scientists on understanding the nature of personnel risks in working with enterprise personnel;

- identification of the socio-economic content of personnel risks, types, and factors of them;

- development of the conceptual framework for managing personnel risks in working with enterprise personnel;

- conducting a comparative analysis of methodological approaches to identifying and assessing personnel risks in working with enterprise personnel;

- conducting a comparative analysis of methodological approaches to managing personnel risks in working with the organization's personnel.

Based on the studies, the author assessed the level of risk of personnel work in practice, which allowed concluding that it is advisable to develop a new risk management system for the personnel of a high-tech enterprise.

Keywords: probability of occurrence of a risk, threat, personnel risks, personnel security, risk level, risk assessment methods, risk mitigation system.

\section{Introduction}

Economic security is a state of protection of an economic entity from internal and external threats and risks that can undermine the stability and development of a socio-economic system and its elements. The following types of security are related to the economic security of an organization: personnel, technical and technological, commodity, information, transport, raw materials, financial, etc.
\end{abstract}


The accumulated practical experience of specialists and research by scientists in the field of security argue that the most important and, at the same time, most complex component of the security of the whole organization is personnel security from the position of ensuring the state of protection of an economic entity from internal and external threats and risks that can undermine its sustainability and socio-economic development.

Of course, entrepreneurial activity is associated with risks, as it requires decision-making in the face of uncertainty. All risks of the organization can be divided into internal and external. External risks are not directly related to the organization's activities, they cannot be managed, but they should be taken into account when planning activities. The level of external risks is determined by such common external factors as economic, political, geographical, social, military, changes in legislation and taxation, etc. We will not dwell on them in more detail, since we are more interested in the internal risks associated with the personnel of the organization.

Internal risks arise directly within the organization, they can and should be managed in order to prevent losses. Factors influencing the level of internal risks are technical safety (risks of equipment malfunction and breakdown), miscalculations of strategic planning, level of information security, human security, financial security, etc.

\section{Methodology}

During the study, methods of observation, comparison and analogy were used, as well as analytical expert estimations. For a deeper understanding of the nature of personnel risks, the approaches to determining personnel risks were examined in detail, and their types and classification features were studied (Akhmetshin, Vasilev, Vlasova, Kazakov, Kotova \& Ilyasov, 2019). On the example of an industrial enterprise, an analysis of trends in the study area was carried out, and indicators of the probability and consequences of personnel risks in the activities of an industrial enterprise were evaluated (Zelentsova \& Tikhonov, 2019).

The key points on risk issues were in the economic concepts of Ulrich Beck and Anthony Giddens (Beck, 1992), John Maynard Keynes, Frank Hyneman Knight (Knight, 2009), and Redhead, K. and Hughes, S. (Redhead \& Hughes, 1988). Studies of Russian and foreign authors have shown that in the quantitative analysis of personnel risks various research methods are used, but the most common are the expert, statistical, and analogy method. Goncharov D.S. focuses on certain assumptions in risk analysis (Goncharov, (2008). Guseva I.B and Kudryashova O.V argue that the most accurate assessment of the degree of risk is provided by statistical research methods, but they can be applied if there is sufficiently complete and reliable information (Guseva \& Kudryashova, 2013). This implies its significant drawback, requiring a large amount of source data on the activities of the enterprise over a long period of time. Kazakova N.A. in her work (Kazakova, 2011) argues that risk analysis can be divided into two complementary types: qualitative and quantitative analysis. Scientists from the State University of Management, Mitrofanova E.A, Mitrofanova A.E., Konovalova V.G., and Svistunov V.M. specialize in the study of personnel risks (Mitrofanova, A.E., Mitrofanova, E.A., Konovalova, Ashurbekov \& Trubitsyn, 2017; Mitrofanova, E.A., Mitrofanova, A.E. \& Simonova, 2019). They believe that personnel risks are assessed by specialists as the most dangerous risks for business. Chrys A. Martin (Martin, 2013) considers risk minimization mechanisms with the help of human resource (HR) specialists to improve labor productivity. Karen Becker and Michelle Smidt believe that with increasing attention to identifying and assessing risks in organizations, personnel management has become a key strategic priority for the development of the organization (Becker \& Smidt, 2016). Jane Bryson examined organizational issues and the determining factors associated with maintaining workforce stability for risk management (Becker \& Smidt, 2016). Most experts consider the risks of personnel regarding the economic security of the organization, as a kind of operational risks or as part of the internal risks of the enterprise, as well as from the standpoint of psychology. Certain issues of personnel risk management in a modern organization are investigated from the standpoint of both personnel management and risk management. However, in most of the available management works, the term "personnel risks" has not yet been fundamentally considered, and the quantity and quality of scientific publications on this issue is not enough to solve problems.

The basis of the methodology of the study is a combination of quantitative and qualitative methods of scientific research.

\section{Results and Discussions}

The author defines human security as the safety of the economic security of an organization from risks and threats associated with personnel, including its intellectual potential and general labor relations in the organization.

The subject of personnel security is the personnel management service and the security service. The object of personnel security is the risks and threats associated with personnel. Personnel, as an internal component of an economic entity, can be considered from the point of view of the principle of four roles: the subject of security, the 
object of security, the source of the threat and the object of the threat (Mitrofanova, Mitrofanova \& Simonova, 2019).

Personnel as a subject of security can act as part of a certain unit: security services and / or other units and persons engaged in activities aimed at risk management and minimizing threats (Feshina, Konovalova \& Sinyavsky, 2019).

Personnel as an object of ensuring security is a protected element of the internal environment from risks and threat: for example, the protection of workers from harmful and dangerous factors that can cause harm to health.

Personnel as a source of threat should be considered as a possible "pest," capable of causing moral and material damage to the organization through their actions and (or) inaction.

Personnel as an object of threat is a component that negative factors and environmental conditions are aimed at.

Experts have proven that approximately $80 \%$ of material damage is caused to the organization by its own personnel. The remaining $20 \%$ of the damage is caused externally as a result of hacking networks and unauthorized access. World statistics suggest that about $15 \%$ of all people in the world are dishonest by definition, the same number of people are completely honest, and the remaining $70 \%$ are hesitant, but at the opportunity they are ready to do something not quite honest.

Today, little attention is paid to personnel risks in practice and in theory, although many organizations are interested in finding the best employees amid a lack of specialists. Personnel potential of the organization depends on the effective management. The person is the most important member in the life of any organization. It is the person who controls the remaining types of risk that affect the economic security of the business entity. Safety is in the hands of the personnel, as the famous statement of the USSR times states: "Rersonnel decide everything" (Kraev \& Tikhonov, 2019).

HR risk management is the awareness of events related to the behavior of personnel that can cause material and moral damage to the enterprise.

It is believed that personnel risks represent a potential possibility of causing moral and material damage to an organization as a result of personnel decisions.

Personnel risk is a dangerous situation of the occurrence of an undesirable event that directly or indirectly affects the sustainability and development of the organization, its personnel, the environment and society. Its danger increases when it is associated with uncertainties in the field of personnel management, its behavior and the external environment.

The sources of personnel risks can be various situations of conflict, such as conflicting interests, an ineffective personnel management system, personnel behavior and the external environment of the organization (Dmitriev \& Novikov, 2019).

The consequences of the implementation of personnel risks can be manifested in lost profit, loss of organization resources, loss of reputation or legal sanctions.

Personnel risks include three essential aspects: risks associated with the adoption of managerial decisions regarding personnel; risks associated with personnel behavior; and risks associated with the impact of external and internal negative factors on the personnel (Levenson, 2005).

Having examined the positions of various authors, we can conclude that the terms "personnel risk", "risk of personnel" and "personnel management risk" in most cases do not differ and mean the probability of occurrence of adverse events related to personnel. Adverse events often include moral and material damage to the organization as a result of the disclosure of confidential information, damage to property or impact on the reputation and image of the organization.

Many organizations, if they consider personnel risks in the organization's management system, do it without any shedule. The risks of personnel are inherently quite difficult; this fact leads to a complex and multidimensional classification. The classification of risks based on various criteria allows us to assess the place of each risk in the overall system, allowing to apply the most accurate risk management methods and increase the effectiveness of risk management (Meyer, Roodt \& Robbins, 2011).

In Russian practice, there are two main groups of personnel risks. The first group is based on a quantitative factor. This group includes the risks of imbalances in the number of employees in organizational units, untimely replacement of jobs, personnel reduction, etc. The second group is based on a qualitative factor. These risks are associated with the mismatch of the required competencies and qualifications of the personnel with the actual state of affairs. Also, there is the risk of personnel disloyalty in the group of qualitative risks, which means that employees do 
not accept the established rules of conduct in the organization (Mitrofanova, Mitrofanova, Konovalova, Ashurbekov $\&$ Trubitsyn, 2017).

Also, in domestic practice, the following two types of personnel risks are distinguished: risks aimed at personnel exposure and risks that come from the personnel themselves.

We suggest dividing all personnel risks into four groups:

- personnel structure risks: unsatisfactory quantitative or qualitative composition of the personnel, unsatisfactory personnel selection procedure, risks at the stage of adaptation of new employees, personnel turnover, etc.;

- risks that arise as a result of the use of HR: low labor productivity, violation of the work schedule (discipline), failure to perform duties, simple working hours, fraud, etc.;

- personnel reserve risks: lack of motivation, inefficiency of personnel reserve, inefficiency of trainings and personnel training, underestimation of employees' potential, etc.;

- risks of dismissal of personnel: loss of reputation of the organization, disclosure of commercial and confidential information, decline in the mood of the labor collective, climate deterioration, various legal proceedings in the process of dismissal, etc.

Personnel risks can be divided according to the damage during their implementation: risks of fraud, theft, replacement and damage, that is, the loss of tangible assets; risks of industrial espionage, distortion of information, disclosure of confidential information, that is, loss of information resources; and risks of reducing the quantitative and qualitative potential of personnel (Ledwidge, 2017). Under the risks of the amount of human capital, the author understands the death or departure of key employees and a decrease in the volume of work they perform. Under the risks of the quality of human capital, the author understands three groups of risks: a change in qualifications, a change in motivation and unplanned results (Bryson, 2013).

A classification sign is the sphere of relationships: risk in the system "person - person", risk in the system "person organizational and technical system", risk in the system "person - environment".

We subdivide personnel risks into qualitative and quantitative. Accordingly, qualitative risks are determined by the qualifications, competence and experience of employees, and quantitative risks reflect the number of personnel and the associated ratios. Separately, the risk of disloyalty as a part of personnel risks is highlighted, which means non-acceptance by employees of the organization's instructions (Martin, 2013).

Personnel risks associated with the adoption of management decisions can be divided into strategic and tactical, respectively, from the level of decision-making. In terms of management, personnel risks associated with making managerial decisions can arise at the highest level (top managers), average (heads of departments) and lower (executors) (Houben, Lenie \& Vanhoof, 2016).

Personnel risks can also be divided into groups according to the following classification criteria: by management functions, by types of losses, by the possibility of diversification, by period of action, by degree of predictability, by degree of affordability, etc (Becker \& Smidt, 2016).

The most complete classification of personnel risks is based on the sources of occurrence. At the same time, external and internal personnel risks are highlighted. Under external personnel risks, the author suggests the likelihood of a negative environmental impact on the safety of the entire organization and on personnel safety, in particular. These include (Cheese, 2016):

1) political: the activity of social movements and parties, the imperfection of legislation, etc.;

2) economic: inflation, unemployment, difficult situations on the labor market, etc.;

3) competitive: more attractive and favorable working conditions for competitors and luring key employees, external pressure on personnel in the form of blackmail and bribery...;

4) social: getting an employee into alcohol, drug, gambling addiction, involvement in a criminal environment;

5) natural: hurricanes, floods, earthquakes, landslides, etc.

Internal personnel risks are closely related to external and are no less dangerous. Sources of internal personnel risks originate within the organization itself. In turn, internal risks are subdivided into personal personnel risks and personnel management risks. Personal risks include the following risks (Kraev, Tikhonov \& Novikov, 2018):

1) biological: the factors of biological risks are usually the age of the employees, the state of their mental and 
physical health; their physical capabilities, etc.;

2) social: the main factors of these risks are the lack of motivation and loyalty, the presence of interpersonal conflicts...;

3) moral: faith, culture, moral values and morality of the employee;

4) intellectual: education, mind, intellect and knowledge;

5) risks of insecurity: negligence, deceit, credulity, criminal record, etc.

HR risks, in turn, can be divided into the following subgroups:

1) risks of labor relations, including a conflict of interests between personnel, a tense socio-psychological climate, a lack of honesty, a lack of measures to restrain employees from illegal actions of employees...;

2) risks of personnel planning, including the imbalance of gender, age and skilled groups, the lack or oversupply of the quantitative composition of the personnel, the lack of definition of positions that can cause significant damage to the organization by their decisions and actions, etc.;

3) risks of inappropriate working conditions, including the suboptimal working hours and a smoke break, the lack of measures to protect the psychological and physical health of workers, poor sanitary and hygienic working conditions, and ineffective working conditions;

4) risks of motivation, including the lack or insufficiency of motivation of personnel to fulfill their duties, the proposal of initiatives in the field of security, the lack of liability of employees, the lack of analysis of the reasons for the dismissal of key employees and their motives, etc.;

5) risks of personnel training and its development, including the lack of training results, unsatisfactory and ineffective training, the inability to implement the acquired knowledge, unsystematic training and certification;

6) risks of personnel assessment, including the lack of assessment of employee loyalty and trustworthiness, subjectivity of assessments, a narrow range of assessments, comparison of employees with one another (instead of with established standards of behavior), an employee's assessment not by its results, but by personal qualities, etc.;

7) risks of social development, including the lack of the necessary social package, the lack of conditions for increasing the level of personnel loyalty, the absence of social guarantees for personnel who have been reduced...;

8) risks of an irrational organizational structure, including the lack of a personnel management department, the mismatch of the number of employees in the development strategy, the inefficiency of the organizational structure, and the optimal distribution of responsibilities and responsibilities in the field of personnel managemen, among others;

9) information support risks, including insufficient training of information security personnel in the field of protecting confidential information and protecting personal data, providing information necessary for employees to work in an incomplete volume and in unsatisfactory quality, etc.;

10) risks of legal support, including the lack of internal local documents regulating personnel safety, the lack of control over the fulfillment of duties of employees in accordance with labor and civil laws, the absence of measures to reduce the likelihood of material liability of employees as a result of labor disputes.

It is worth saying that each organization has the right to independently develop a list of personnel risk groups, taking into account its resources, capabilities, focus of activity, industry, attitude to risk and the main characteristics of its personnel (Cascio \& Boudreau, 2014). However, as we have found out, the qualitatively and comprehensively disclosed classification of personnel risks allows the company to get to know all the nuances of risk management and to choose the most suitable method of managing and reducing risk for its specific groups. To ensure personnel safety, it is necessary to understand what the personnel risk management system is and what elements it consists of, how personnel risks are managed in the organization and who is responsible for them (Tikhonov, Sazonov \& Novikov, 2019).

For an objective assessment of personnel risk by the example of a number of industrial enterprises in Chuvashia (Russia), an integral approach was used, which consists in calculating the integral level of personnel risks, reflecting the cumulative effect of personnel risks on the plant. In order to identify the most significant personnel risks, it is 
necessary to assess all groups of personnel risks. In the analysis, we will use the HR risk classification approach, which includes 3 risk groups (Sychugov, Akhmetshin, Grishin, Shpakova \& Plotnikov, 2019):

1) risks associated with the selection of personnel;

2) risks associated with the impact of negative factors on the personnel (harm to the health of employees);

3) risks associated with the behavior of personnel (corporate fraud, corruption, disclosure of confidential information, etc.);

4) risks associated with qualifications, knowledge and experience of personnel;

5) risks arising at the stage of dismissal.

In order to identify the significance of each group of personnel risks, we will use the method of expert assessment using two criteria: the probability of the occurrence of personnel risks and the magnitude of the consequences of the implementation of personnel risks.

It is proposed to calculate the integrated assessment of each group of personnel risks using the following formulas:

$$
X_{i}=\frac{\sum_{k=1}^{n} X_{i k}}{n},
$$

where $\boldsymbol{X}_{\boldsymbol{i}}$ is the general expert assessment of the likelihood of the occurrence of personnel risks of the i-th group; $\boldsymbol{X}_{\boldsymbol{i} \boldsymbol{k}}$ is the assessment by the k-th expert of the probability of the implementation of personnel risks of the i-th group; $\mathrm{k}$ is the serial number of the subject of the assessment (expert) (from 1 to $\mathrm{n}$ ).

$$
Y_{i}=\frac{\sum_{k=1}^{n} Y_{i k}}{n},
$$

where $\boldsymbol{Y}_{\boldsymbol{i}}$ is the general expert assessment of the magnitude of the consequences of the implementation of personnel risks of the i-th group;

$\boldsymbol{Y}_{\boldsymbol{i} \boldsymbol{k}}$ is the assessment by the k-th expert of damage from the implementation of personnel risks of the i-th;

$\mathrm{k}$ is the serial number of the subject of the assessment (expert) (from 1 to $\mathrm{n}$ ).

$$
I_{i}=\frac{\sum_{k=1}^{n}\left(X_{i k} \times Y_{i k}\right)}{n},
$$

where I is the significance of the $\mathrm{i}$-th group of personnel risks for the enterprise.

To implement the expert assessment method, a specialized questionnaire for experts and a system of indicators reflecting the state of personnel risks were developed. Speaking as experts, the survey involved managers and employees of the main divisions of the company, including the security service and the HR department of the enterprise in question. A total of 19 experts participated in the survey. They were provided with probability and damage assessment scales presented in Table 1 and 2, respectively, and questionnaires (table 3), which include the following blocks of questions.

The probability of the occurrence of personnel risks of the i-th group was proposed to be assessed by experts on the scale presented in Table 1.

Table 1. Probability scale for the implementation of personnel risks of the i-th group

\begin{tabular}{ccc}
\hline $\begin{array}{c}\text { Probability of the implementation of } \\
\text { personnel risk, } \%\end{array}$ & $\begin{array}{c}\text { Probability of the implementation of } \\
\text { personnel risk (expert assessment) }\end{array}$ & Score \\
\hline 0 & Impossible & 0 \\
$1-15$ & Very low (very unlikely) & 1 \\
$15-30$ & Low (unlikely) & 2 \\
$30-50$ & Medium (possible) & 3 \\
$50-70$ & High (likely) & 4 \\
$70-100$ & Very high (often) & 5 \\
\hline
\end{tabular}

Source: developed by the author 
The significance of the damage from the implementation of the personnel risks of the i-th group was proposed to be assessed by experts on the scale presented in Table 2 .

Table 2. Scale of the degree of damage from the implementation of personnel risks of the $\mathrm{i}$-th group

\begin{tabular}{ccc}
\hline Degree of damage in \% of profit & Degree of damage (expert assessment) & Score \\
\hline 0 & Neutral & 0 \\
$0,1-0,2$ & Weak & 1 \\
$0,2-0,5$ & Moderate & 2 \\
$0,5-0,7$ & Average & 3 \\
$0,7-1$ & Substantial & 4 \\
$1-1,5$ & Significant & 5 \\
$1,5-10$ & Strong & 6 \\
$10-15$ & Very strong & 7 \\
$15-50$ & Critical & 8 \\
$50-100$ & Destructive & 9 \\
\hline
\end{tabular}

Source: developed by the author.

Table 3. Expert questionnaire

\begin{tabular}{|c|c|c|c|}
\hline HR risk group & Risk description & $\begin{array}{l}\text { Probability of } \\
\text { implementation }\end{array}$ & $\begin{array}{c}\text { Degree of } \\
\text { damage }\end{array}$ \\
\hline Recruiting risks (1) & $\begin{array}{l}\text { The risk of an incorrect assessment of the } \\
\text { candidate, the reliability of the data provided by } \\
\text { him }\end{array}$ & & \\
\hline $\begin{array}{l}\text { Risks associated with the } \\
\text { impact of negative factors } \\
\text { on personnel (2) }\end{array}$ & $\begin{array}{l}\text { The risk of harm to health by dangerous and } \\
\text { harmful factors of the enterprise and, as a } \\
\text { consequence, the need to pay compensation and } \\
\text { fines; risk of harm to health by third parties or by } \\
\text { the environment of the enterprise }\end{array}$ & & \\
\hline $\begin{array}{l}\text { Risks associated with } \\
\text { personnel behavior (3) }\end{array}$ & $\begin{array}{l}\text { The risk of theft of assets, corporate swindle, } \\
\text { corruption, fraud, sabotage, disclosure of trade } \\
\text { secrets; the risk of damage to equipment, errors that } \\
\text { can lead to material and moral damage to the } \\
\text { company }\end{array}$ & & \\
\hline $\begin{array}{l}\text { Risks associated with } \\
\text { personnel qualifications, } \\
\text { knowledge and experience } \\
\text { (4) }\end{array}$ & $\begin{array}{l}\text { The risk of formation of an ineffective personnel } \\
\text { reserve, organization of certification, career plan }\end{array}$ & & \\
\hline $\begin{array}{l}\text { Risks arising from the } \\
\text { termination of employment } \\
\text { (5) }\end{array}$ & $\begin{array}{l}\text { The risk of sanctions by court order, damage to the } \\
\text { reputation of a dismissed employee, disclosure of } \\
\text { confidential information }\end{array}$ & & \\
\hline
\end{tabular}

Source: developed by the author

The level of integral assessment of personnel risk is calculated by the following formula:

$$
I_{p r}=\frac{\sum_{i=1}^{5} S_{i}}{50}
$$

where $\boldsymbol{S}_{\boldsymbol{i}}$ is the significance of the impact of the $i$-th group of personnel risks of the enterprise;

$i$ is personnel risk group number; 
50 is the maximum possible value of the impact of the $i$-th group of personnel risks.

$\boldsymbol{S}_{\boldsymbol{i}}$ is the significance of the impact of the $i$-th group of personnel risks of the enterprise is determined by multiplying the probability of the occurrence of personnel risk and the magnitude of the consequences of the occurrence of personnel risk and is calculated by the formula:

$$
S_{i}=\rho_{i} * N_{i},
$$

where $\boldsymbol{\rho}_{\boldsymbol{i}}$ is the weight coefficient of the $i$-th personnel risk;

$\boldsymbol{N}_{\boldsymbol{i}}$ is the strength of the $i$-th personnel risk impact on the enterprise.

As a result of the survey, there were obtained data, on which the level of integral assessment of personnel risk was calculated. Its value was corresponded to the average degree of personnel riskiness of the enterprise. The results of the author's calculations according to the proposed model correspond to the main indicators of the enterprise's activities for 2017-2019, which allows concluding about the possible practical application of this study.

\section{Conclusion}

Experts from the managerial staff of the enterprise carried out diagnostic tests, which basically confirmed the correctness of the research methodology and the relevance of the results for making decisions. Having studied the work of the enterprise in the functional departments and in the field of personnel management, significant shortcomings were identified by the author and experts. To eliminate them, it is necessary to create an effective personnel risk management system for an industrial enterprise. The goal of improving such a personnel risk management system for an industrial firm may be to increase the efficiency of both personnel management and planned achievement of goals, as well as to reduce the likelihood of unforeseen losses.

The tasks of the personnel risk management system of an industrial enterprise may be:

- creation of a single information space about personnel and their risks;

- development of methods for identifying personnel risks;

- determination of the sources and causes of identified personnel risks;

- assessment of possible damage from the implementation of personnel risks;

- determination of the possibility of reducing the possibility of the implementation of personnel risk and the of reducing damage in case of the implementation of personnel risks, determining the required resources and their distribution;

- development of a method for assessing the effectiveness of measures to reduce personnel risks;

- development of measures to minimize personnel risks and their application in practice;

- control over the implementation of measures taken;

- assessment of the effectiveness of measures taken and adjustment of management decisions.

Thus, according to the results of the study, the author revealed the socio-economic nature of personnel risks and defined the concept of "personnel risk", which is the probability of an adverse outcome that could lead to losses as a result of incorrect management decisions about personnel, illegal actions (inactions), personnel behavior and the impact of negative factors on personnel. The author developed his approach to the classification of personnel risks based on the above three essential aspects of personnel risk. The assessment was carried out, which made it possible to draw conclusions about the level of enterprise risk in terms of personnel work. The result can be characterized as satisfactory, which indicates the need for measures to improve the personnel risk management system. There are elements and mechanisms of development of the personnel risk management system, which can be used for organizational and economic analysis of enterprises of high-tech Russian industries.

\section{References}

Akhmetshin, E. M., Vasilev, V. L., Vlasova, N. I., Kazakov, A. V., Kotova, X. Y., \& Ilyasov, R. H. (2019). Improving Management Functions at an Enterprise: Levels of the Internal Control System. Quality - Access to Success, 20(171), 39-43.

Beck, U. (1992). Risk Society, Towards a New Modernity. London: Sage Publications.

Becker, K., \& Smidt, M. (2016). A risk perspective on human resource management. Human Resource Management Review, 26(2), 149-165. 
Bryson, J. (2013). Managing HRM risk in a merger. Employee Relations, 25(1), 14-30.

Cascio, W., \& Boudreau, J. (2014). HR strategy: optimizing risks, optimizing rewards. Journal of Organizational Effectivenes, 1(1), 77-97.

Cheese, P. (2016). Managing risk and building resilient organisations in a riskier world. Journal of Organizational Effectivenes, 3(3), 323-331.

Dmitriev, O. N., \& Novikov, S. V. (2019). Economic Optimization of the Modular Structure of Complex Objects. Russian Engineering Research, 39(6), 503-506.

Feshina, S. S., Konovalova, O. V., \& Sinyavsky, N. G. (2019). Industry 4.0-transition to new economic reality. Studies in Systems, Decision and Control, 169, 111-120.

Goncharov, D. S. (2008). An integrated approach to risk management for Russian companies. Moscow: Apex.

Guseva, I. B., \& Kudryashova, O. V. (2013). Research of approaches to risk assessment of R\&D. Science in Central Russia, 4, 94-96.

Houben, G., Lenie, K., \& Vanhoof, K. (2016). A knowledge-based SWOT-analysis system as an instrument for strategic planning in small and medium sized enterprises. Decision Support Systems, 26, 125-135.

Kazakova, N. A. (2011). The financial environment of entrepreneurship and entrepreneurial risks. Textbook. Moscow: INFRA-M.

Knight, F. H. (2009). Risk, Uncertainty and Profit (1921). University of Illinois at Urbana-Champaign's Academy for Entrepreneurial Leadership Historical Research Reference in Entrepreneurship. Retrieved from https://ssrn.com/abstract=1496192

Kraev, V. M., \& Tikhonov, A. I. (2019). Risk Management in Human Resource Management. TEM Journal, 8(4), 1185-1190.

Kraev, V. M., Tikhonov A. I., \& Novikov, S. V. (2018). Economic Conversion in the Aviation Industry. Russian Engineering Research, 38(4), 330-333.

Ledwidge, J. (2017). Corporate social responsibility: the risks and opportunities for HR. Human Resource Management International Digest, 15(6), 27-30.

Levenson, A. (2005). Harnessing the power of HR analytics. Strategic HR Review, 4(3), 28-31.

Martin, C. A. (2013). Auditing HR-practices for risk management. Davis Wright Tremaine, 5(2), 1-25.

Meyer, M., Roodt, G., \& Robbins, M. (2011). Human resources risk management: governing people risks for improved performance. Journal of Human Resource Management, 9(1), 1-12.

Mitrofanova, A. E., Mitrofanova, E. A., Konovalova, V. G., Ashurbekov, R. A., \& Trubitsyn, K. V. (2017). Human resource risk management in organization: methodological aspect. Proceedings of the International Conference on Trends of Technologies and Innovations in Economic and Social Studies, 699-705.

Mitrofanova, E. A., Mitrofanova, A. E., \& Simonova, M. V. (2019). Sectoral framework of qualifications as a tool for the integration of educational and business spheres of Russia. Contributions to Economics, 275-296.

Redhead, K., \& Hughes, S. (1988). Financial Risk Management. Cambridge: Gower.

Sychugov, A. A., Akhmetshin, E. M., Grishin, V. M., Shpakova, R. N., \& Plotnikov, A. V. (2019). Algorithm determine trust value to the distributed information systems elements. Journal of Mechanical Engineering Research and Developments, 42(2), 6-9.

Tikhonov, A. I., Sazonov, A. A., \& Novikov, S. V. (2019). Digital Aviation Industry in Russia. Russian Engineering Research, 39(4), 349-353.

Zelentsova, L. S., \& Tikhonov, A. I. (2019). Differential-integral approach to the competition resistance evaluation of aircraft engine manufacturing organization. TEM Journal, 8(1), 165-170. 